\title{
Vertical banded gastroplasty in the treatment of morbid obesity: results of three year follow up
}

\author{
N D CARR, R A HARRISON, A TOMKINS, RACHEL BAUGHEN, \\ SUZANNE DEMMER, JILL GODFREY, AND C G CLARK
}

From the Department of Surgery, University College and Middlesex Hospital, School of Medicine, The Rayne Institute, London, and Clinical Nutrition Unit, London School of Hygiene and Tropical Medicine, London

SUMMARY Vertical banded gastroplasty has replaced jejunoileal bypass in the surgical treatment of morbid obesity. Although this procedure carries a low incidence of early postoperative complications there is little information on either longer term follow up or the impact on nutritional status. The present study describes the outcome in 42 patients with morbid obesity who underwent vertical banded gastroplasty and were followed up in a special nutrition clinic between nine and 36 months postoperatively. Body mass index (BMI) fell from a preoperative value of $47 \cdot 4(6 \cdot 7) \mathrm{kg} / \mathrm{m}^{2}$ (mean (SD)) to $37 \cdot 5(5 \cdot 8), 35(6 \cdot 2), 33 \cdot 9(6 \cdot 1)$, and $33 \cdot 1(5 \cdot 7) \mathrm{kg} / \mathrm{m}^{2}$ at $6,12,24$, and 36 months respectively. Immediate postoperative complications were minimal but during follow up four patients developed stenosis of the gastroplasty stoma and required reoperation. Plasma albumen concentrations were maintained but three patients developed iron deficiency anaemia. Most patients were able to eat a normal diet in reduced quantities and noted a marked improvement in the quality of life. The benefits and safety of vertical banded gastroplasty suggest an important role for this operation in the management of morbid obesity.

Although jejunoileal bypass is effective in the surgical treatment of morbid obesity, this operation has an unacceptably high incidence of late metabolic complications.' As a result jejunoileal bypass has now been largely abandoned and superseded by gastric reduction surgery. In 1967 Mason introduced gastric bypass ${ }^{2}$ in which the stomach was partitioned and the proximal pouch anastomosed to a loop of jejunum. This procedure produced excellent longterm weight loss but was technically demanding and associated with a significant perioperative complication rate. Concurrently, in an attempt to improve the safety of gastric restrictive operations the concept of gastroplasty was introduced..$^{3}$ In this type of operation a small proximal gastric pouch is constructed and connected to the remainder of the stomach by a narrow stoma. Because the first gastroplasty numerous modifications have been developed. One

Address for correspondence: Dr A M Tomkins, Department of Surgery, University College and Middlesex Hospital, School of Medicine, 5 University Street, London WC1E 6JJ.

Accepted for publication 4 January 1989. variation currently under evaluation in a number of centres is the vertical banded gastroplasty devised by Mason. ${ }^{4}$ Although this procedure is associated with a low incidence of early postoperative complications and satisfactory weight loss in the short term, there have been few descriptions of longer term results. The aim of the present study was to assess the outcome in 42 patients who have undergone vertical banded gastroplasty in the treatment of morbid obesity.

\section{Methods}

DEFINITION OF MORBID OBESITY

The body mass index (BMI = weight in $\mathrm{kg} /$ height in metres $\left.{ }^{2}\right)$ was used to express the degree of obesity. Normal BMI ranges from 20 to 25; a value of greater than 39.0 being indicative of morbid obesity."

PATIENT SELECTION CRITERIA

Each patient had tried to lose weight on several occasions but any weight reduction had not been 
sustained. Considerable time was spent in assessment of suitability and counselling preoperatively. This included interviews with patients who had already undergone vertical banded gastroplasty, a specially prepared information booklet describing the operation and its potential complications, interviews with the dietitians and regular attendance at the Surgical Nutrition Clinic run jointly by a physician, a surgeon, a dietitian and a nurse/nutritionist. Patients were also admitted to hospital for a two week period in which a controlled diet ( $500 \mathrm{kcal} /$ day) was provided and their willingness to participate in a rigid physiotherapy/ activity programme was assessed. Nearly all patients were depressed about their severe morbidity but if any patient showed features of severe emotional problems or were unwilling to participate fully in the assessment programme, surgery was not advised. Of 97 patients with a BMI of more than 39.0 who were referred for vertical banded gastroplasty, only 42 were considered suitable on medical and psychological grounds.

\section{OPERATIVETECHNIQUE}

Details of the technique of vertical banded gastroplasty have been published elsewhere ${ }^{h}$ and follow the original description of Mason. ${ }^{+}$After good exposure of the upper abdomen a circular stapling device (25 $\mathrm{mm}$ diameter) was used to punch a hole through the stomach close to the lesser curve. The vertical part of the pouch was then completed with two applications (four rows) of a linear stapling device $(90 \mathrm{~mm})$. The stoma was then encircled with a piece of Marlex mesh $1.5 \times 5.5 \mathrm{~cm}$ in circumference, which was in turn covered with a piece of adjacent omentum. A pouch the size of $40 \mathrm{ml}$ or less is recommended (Fig. 1). The stomach was decompressed through a nasogastric tube placed through the stoma for the first 24 hours after operation.

POSTOPERATIVE MANAGEMENT

Oral fluids were reintroduced during the first three or four postoperative days. Patients were advised to consume homogenised food for eight weeks. This was sometimes supplemented by sip feeds such as Ensure (Abbott). Patients were warned about foods such as white bread, oranges and red meat, which many found difficult to swallow. Similarly, they were warned about high energy foods, such as chocolate, ice cream, biscuits, and sweet drinks.

Patients were seen regularly at the Surgical Nutrition Clinic. In addition an informal 'support club' was started for these patients. Body weight was recorded in light outdoor clothes without shoes on an electric scale reading to $0.1 \mathrm{~kg}$. Measurement of plasma albumen and haemoglobin was performed regularly. Dietary intake was assessed by informal

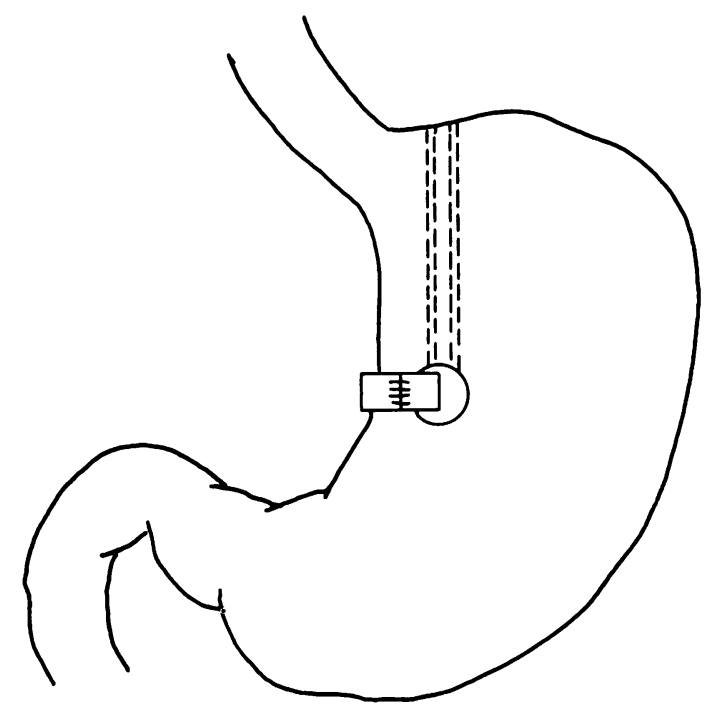

Fig. 1 Diagram showing completed vertical banded gastroplasty.

interview and records kept by the patients. Oral iron (ferrous sulphate $200 \mathrm{mg}$ twice daily) was prescribed for those whose dietary iron intake was low.

QUALITY OF LIFE

A group of 19 patients who had been operated on between 12 and 24 months previously was interviewed by one of us (SD) who was not a member of the Surgical Nutrition Clinic and therefore less liable to influence the response to questions. The interview elucidated the attitudes of the patients towards a number of life situations outlined in Table 1.

\section{Results}

PATIENTS STUDIED

During the period between September 1982 and December 1986 vertical banded gastroplasty was performed on 45 patients who had previously not

Table 1 Change in quality of life after vertical banded gastroplasty

\begin{tabular}{llll}
\hline & Improved & No change & Worse \\
\hline Dyspnoea & 19 & 0 & 0 \\
Satisfaction with life & 14 & 4 & 1 \\
Social participation & 13 & 6 & 0 \\
Exercise ability & 12 & 7 & 0 \\
Relationship with family & 11 & 8 & 0 \\
Relationships with colleagues & 11 & 8 & 0 \\
Joint pain & 8 & 11 & 0 \\
\hline
\end{tabular}


Table 2 Follow up in 42 patients who underwent vertical banded gastroplasty

\begin{tabular}{lcccc}
\hline Patients $(n)$ & \multicolumn{5}{c}{ Time of follow up $(\mathrm{mo})$} \\
\hline & 6 & 12 & 24 & 36 \\
Available for follow up & 42 & $41^{*}$ & $30 \dagger$ & $15 \ddagger$ \\
Followed up & 41 & 36 & 27 & 12 \\
Absconded from follow up & 1 & 3 & 1 & 3 \\
Revision required & - & 2 & 2 & - \\
\hline
\end{tabular}

*One patient less than 12 months postop; $† 12$ patients less than 24 months postop; $\ddagger 22$ patients less than 36 months postop.

undergone surgery for morbid obesity. There were 36 women and six men (age range 29-48 years, mean age $42 \cdot 2$ years). The mean preoperative body weight was $130.0(3.3) \mathrm{kg}$ (mean (SEM)) with a mean BMI of $47 \cdot 4(1.0) \mathrm{kg} / \mathrm{m}^{2}$ (mean (SEM)). Follow up data are detailed in Table 2.

\section{CHANGE IN BODY MASS INDEX}

Body mass index showed a rapid decline during the first postoperative year and fell from a preoperative value of $47 \cdot 4 ; \mathrm{SD}(6 \cdot 7) \mathrm{kg} / \mathrm{m}^{2}$ to $37 \cdot 5 ; \mathrm{SD}(5 \cdot 8) \mathrm{kg} / \mathrm{m}^{2}$, and $35.0 ; \mathrm{SD}(6 \cdot 2) \mathrm{kg} / \mathrm{m}^{2}$ at six and 12 months respectively. Over the second postoperative year the rate of decrease in BMI became less marked but continued to fall. At the end of this time period BMI was $33.9 ; \mathrm{SD}(6 \cdot 1) \mathrm{kg} / \mathrm{m}^{2}$. One hundred per cent, $94 \%$, and $75 \%$ of patients reviewed at six, 12 , and 24 months were still losing weight. Twenty three of 41 $(56 \%), 25$ of $36(69 \%)$, and 22 of $27(82 \%)$ patients who were reviewed at six, 12 , and 24 months respectively exhibited a BMI of less than $39.0 \mathrm{~kg} / \mathrm{m}^{2}$.

Twelve of the 15 patients available for follow up at three years were reviewed at this time (Table 2). In ten of these patients BMI remained below $39.0 \mathrm{~kg} / \mathrm{m}^{2}$ (Fig. 2).

\section{POSTOPERATIVE COMPLICATIONS}

\section{Immediate}

There were no deaths in this series and perioperative complications were of a minor nature in the majority of patients (Table 3 ).

\section{Late vomiting}

This was the most common problem and occurred in nine patients (Table 3). No apparent cause for this symptom could be identified in three patients and in another two patients temporary bolus obstruction of the stoma had occurred. Revisional surgery was required in the other four patients who had developed stenosis of the gastroplasty stoma (mean time $14.8(5.3)$ months postgastroplasty) and in whom repeated endoscopic dilatation had failed

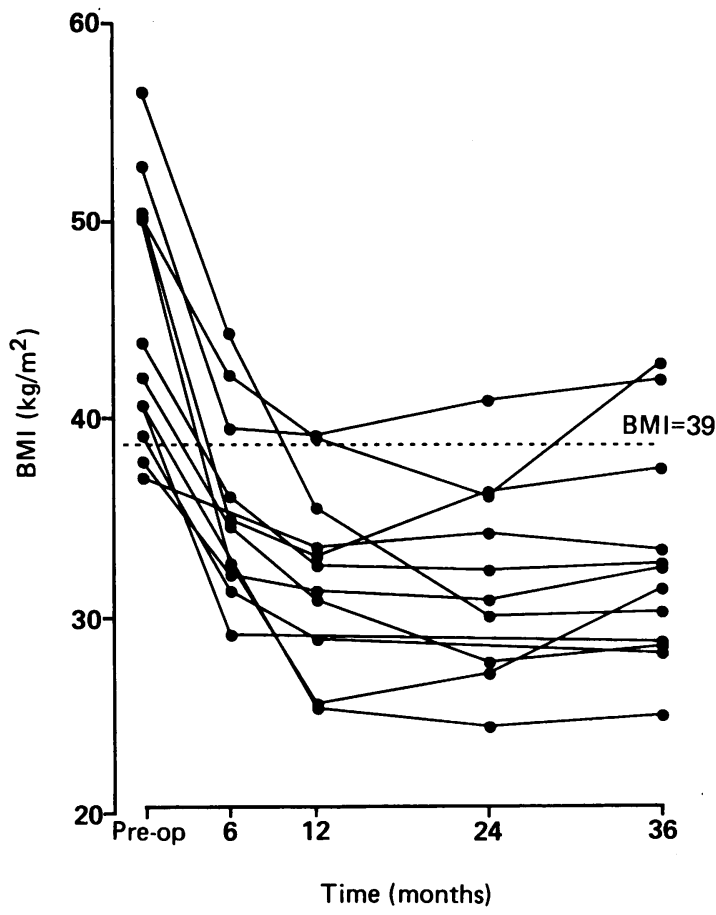

Fig. 2 Body mass index (BMI) versus time in 12 patients who were followed for three years after vertical banded gastroplasty (VBG).

to control their vomiting. Two of these patients requested that the procedure be reversed and removal of the Marlex collar was the only procedure undertaken. Since reoperation both these patients have regained their original weight within six months of surgery. In the other two patients excision of the Marlex mesh was accompanied by the construction of a Roux-en-Y gastric bypass. In these patients BMI has remained low at 24.9 and $31.5 \mathrm{~kg} / \mathrm{m}^{2}$ for 18 and 30 months post-revision.

\section{BIOCHEMICAL AND HAEMATOLOGICAL STATUS (Table 4)}

Plasma albumen concentrations were maintained within normal levels for the duration of the study, despite massive reductions in body weight. There was a slight decrease in the haemoglobin concentration gastroplasty and three patients had iron deficiency anaemia at 36 months (Hb of $8 \cdot 5,2$, and $11.5 \mathrm{~g} / \mathrm{dl}$ ). Two of these patients, however, developed increasingly heavy periods during the years after their gastroplasty. All three patients had received oral iron tablets but in each case consumption was very intermittent. 
Table 3 Postoperative complications in 42 patients who underwent vertical banded gastroplasty

\begin{tabular}{ll}
\hline & Patients $(n)$ \\
\hline Immediate: (<1 month) & \\
Chest infection & 7 \\
Minor wound infection & 2 \\
Superficial wound dehiscence & 2 \\
Calf vein thrombosis & 1 \\
Pulmonary embolism & 1 \\
Late: $(>1$ month) & 9 \\
Vomiting: & 3 \\
$\quad$ No cause found & 2 \\
Bolus obstruction & 4 \\
Stomal stenosis & 1 \\
Incisional hernia & \\
\hline
\end{tabular}

\section{EATING PATTERNS}

\section{Preoperatively}

All patients gave a history of excessive energy intake, although this was not always admitted at the first interview.

\section{Postoperatively}

It was not easy to categorise the eating patterns because of the considerable variation in dietary intake from day to day. Some degree of restriction of dietary intake was noted, however, by 39 of 41 (95\%) patients at six months, 32 of $36(88 \%)$ patients at 12 months, 22 of $27(81 \%)$ patients at 24 months, and eight of $12(67 \%)$ at 36 months. Only one patient continued to take the prescribed homogenised diet for eight weeks, the remainder found the sight of the food to be too unappetising. There was no consistent pattern about types of food that caused oesophageal discomfort or temporary blockage of the outlet but $46 \%$ of patients complained that discomfort occurred if food and drink were taken within half an hour of each other.

\section{QUALITY OF LIFE}

\section{Preoperatively}

All patients expressed feelings of despair and low self esteem. This was accompanied by problems in interpersonal relationships with their spouses, families, and colleagues at work. Each was sufficiently embarrassed by her/his obesity to avoid participation in social activities. Only two patients attempted any form of regular exercise, the remainder could not or would not take anything but minimal activity, and all complained of restrictions in performing tasks such as shopping and housework. Severe joint pain (back, knees, ankles, or all three) was noted by 11 subjects, and all complained of severe dyspnoea on excretion.
Table 4 Plasma albumen and haemoglobin concentrations after vertical banded gastroplasty

\begin{tabular}{llll}
\hline & 12 months & 24 months & 36 months \\
\hline Plasma albumin $(\mathrm{g} / \mathrm{l})$ & $42(4 \cdot 2)$ & $39(3 \cdot 7)$ & $42(3 \cdot 5)$ \\
Haemoglobin $(\mathrm{g} / \mathrm{dl})$ & $13 \cdot 2(1 \cdot 6)$ & $12 \cdot 8(1 \cdot 4)$ & $12 \cdot 0,1 \cdot 9)$ \\
\hline
\end{tabular}

Mean (SD).

Postoperatively (Table 1)

There was considerable improvement in the emotional state and the gain in self esteem was noticeable. This was associated with considerable improvement in interpersonal relationships and in confidence, sufficient to travel on public transport and socialise. All patients experienced improvement in their dyspnoea. Assessment of changes in joint pain was difficult but the majority reported improvement.

Those with less satisfactory improvement appeared to be those with the severest emotional problems preoperatively. The single patient who complained of a deterioration in quality of life had required two laparotomies - one for intestinal adhesions and one to remove the Marlex mesh.

\section{Discussion}

For the purposes of the present study BMI was chosen as the most satisfactory criterion for the definition of morbid obesity. This index has the advantage over calculation of percentage excess weight for height in that it avoids the need for constant reference to standard weight and height charts. Several studies emphasise the major health problems that obese patients experience and indicate that a BMI of greater than 39 is associated with a significant increase in the risk of death from obesity related illness. ${ }^{7-4}$ The aim of vertical banded gastroplasty in the present study was to reduce BMI towards levels at which risk of obesity associated illness is reduced. This was achieved in the majority of patients during the first postoperative year. It has been emphasised that for gastroplasty to be effective this early weight loss, which has been shown by other authors, ${ }^{1014}$ should be maintained during the follow up period. Despite intensive efforts it was not possible to keep in contact with all patients and our data may be biased towards more favourable weight loss if there were several with poor weight loss amongst the defaulters from follow up. Nevertheless, our findings indicate that in many patients a reduction in BMI may be maintained for up to three years after surgery. 
Gastroplasty achieves the objective of weight reduction by physically limiting the size of a meal and the speed at which patients can eat. ${ }^{15}$ These dietary restrictions can be overcome by deliberately consuming high energy foods and fluids and by eating more frequently. Failure to lose weight and weight gain in the late postoperative period have been noted by several authors after vertical banded gastroplasty. $1111131+16$ This may be because of stoma dilatation and staple line dehiscence in a small proportion of patients. ${ }^{11114}$ Shamblin et al, ${ }^{17}$ have emphasised, however, that the principal cause of failure to lose weight is non-compliance with postoperative dietary advice. These observations emphasise the need for careful patient selection. The criteria used in the present study appear similar to those used by others $^{1216}$ who have stressed that patients should be well motivated, psychiatrically stable and fully informed about the nature and effects of gastroplasty. Moreover, even with careful selection criteria the importance of continued emotional support and dietary advice cannot be over emphasised.

The findings from the present study are in agreement with those of other authors who have shown that vertical banded gastroplasty is a safe operation in the surgical treatment of morbid obesity. 1111.314 Leakage from staple lines ${ }^{13.14}$ and operative injury to the oesophagus, stomach ${ }^{11}$ and spleen ${ }^{11}$ have produced problems in some series but none of these complications were encountered in our patients. Severe vomiting is a well documented symptom after vertical banded gastroplasty and can occur in up to $19 \%$ of patients. ${ }^{18}$ As noted by Shearman et al ${ }^{12}$ this may occur early in the postoperative period because of stomal oedema and inflammation of the pouch. Alternatively it can develop after several months as a result of fibrosis around the stoma. The aetiology of this is unknown but may be related to local ischaemia or reaction to the Marlex mesh. ${ }^{14}$ The management of this compliation is controversial but Al-Halees et al ${ }^{\text {1. }}$ have advocated a conservative approach to treatment which consists of enteral and parenteral nutritional support together with repeated endoscopic dilatation of the stoma. These measures were successful in 32 of 33 of their patients and the authors further stated that reoperation is seldom necessary, even when the degree of stenosis is severe. Our experience contrasts with this and supports the opinion of Shamlin et al ${ }^{17}$ and Dietal et al $l^{10}$ that endoscopic dilatation seldom relieves the symptoms of pouch outlet obstruction and that these patients should be offered revisional surgery. Dietal et al ${ }^{\prime \prime \prime}$ have drawn attention to the rapid weight gain which follows removal of the Marlex collar or simple gastro-gastrostomy only and our results support this conclusion. Providing that these patients wish to maintain their weight loss, conversion to Roux-en-Y gastric bypass appears to be acceptable..$^{13}$

In view of the severe dietary restriction after vertical banded gastroplasty and the considerable weight loss that these patients achieved, we were concerned lest there be an excessive loss of lean body mass. In a previous study of a group of these patients, however, we showed normal values for the contractile properties of skeletal muscle. ${ }^{19}$ The maintenance of plasma albumen concentrations during the weight loss further supports the proposition that lean body mass is lost in proportion to body weight. Other studies have concentrated on a wide range of nutritional parameters after vertical banded gastroplasty. Vitamin and trace element deficiencies appear to be a problem in a proportion of patients studied 12 months after gastroplasty ${ }^{21}$ but information on longer follow up is not avaialble. Iron deficiency, in particular, seems likely to occur. The rather small number of patients with anaemia, which could sometimes be attributable to vaginal blood loss, on our study may reflect our practice of advising on oral iron therapy at an early stage.

A further question in the management of these patients is the optimum feeding regime in the postoperative months. We had hoped to reduce the symptoms of pain and vomiting that some of our patients experienced by insisting on a homogenised diet. In fact, our patients declined to keep to this regime which we now regard as too rigid; instead, an adequate intake of formula feeds should be ensured.

Patients with morbid obesity usually fail to reduce their weight significantly by diet alone. 2122 They become increasingly incapacitated, miserable and ill. In view of the severe problems which have followed previous methods of gastrointestinal surgery for weight reduction ${ }^{23}$ we are cautious in predicting longterm results. The dramatic weight reduction and striking improvement in quality of life with minimal surgical complications, however, are sufficient to warrant further evaluation of this procedure.

\section{References}

1 Siamak AA, Stanko RT. Perspectives on gastrointestinal surgery for treatment of morbid obesity. Gastroenterology 1984; 87: 1381-91.

2 Mason EE, Ito C. Gastric surgery for the relief of morbid obesity. Surg Clin North Am 1967; 47: 1345-51.

3 Printon KJ. Mason EE. Gastric surgery for the relief of morbid obesity. Arch Surg 1973; 106: 428-31.

4 Mason EE. Vertical banded gastroplasty for obesity. Arch Surg 1982; 117: 701-6.

5 Linner JH. Gastric operations: General principles. In: Surgery for morbid obesity. New York: SpringerVerlag. 1984: 55-6.

6 Harrison RA. Clark CG. Vertical banded gastroplasty: 
operation for morbid obesity. Ann Coll Surg Engl 1984; 66: $346-7$.

7 Garrow JS. Treat obesity seriously: a clinical manual. London: Churchill Livingstone, 1981.

8 Drenick EJ. Definition and health consequences of morbid obesity. Surg Clin North Am 1979; 55: 963-76.

9 Italic TBV. Morbid obesity: a hazardous disorder that resists conservative treatment. Am J Clin Nutr 1980; 33: $358-63$.

10 Dietal M, Jones BA, Petrov I, Stainislaw RW, Surinder B. Vertical banded gastroplasty: results in 233 patients. Can J Surg 1986; 29: 322-4.

11 Hocking MP, Kelly KA. Callaway CW. Vertical banded gastroplasty for morbid obesity: clinical experience. Mayo Clin Proc 1986; 68: 139-42.

12 Shearman CP, Baddeley RM. Which gastroplasty for the correction of massive obesity? Ann R Coll Surg Engl 1986; 68: $139-42$.

13 Eckhout GV, Willbanks OL, Moore JT. Vertical ring gastroplasty for morbid obesity: five year experience with 1463 patients. Ann J Surg 1986; 152: 713-6.

14 Makarewicz PA, Freeman JB, Burchett RN, Brazeau P. Vertical banded gastroplasty. Assessment of efficacy. Surgery 1985; 98: 700-7.

15 Villar HV, Wangensteen SL, Burks TF, Patton DD.
Mechanisms of saticty and gastric emptying after gastric partitioning and bypass. Surgery $1981 ; 90: 229-36$.

16 Maclean LD, Rhode BM. Shizgal HM. Gastroplasty for obesity. Surg Gynecol Obstet 1981; 153: 20()-8.

17 Shamblin JR, Shamblin AE. Gastroplasty in morbid obesity: observations in 300 patients. South Med J 1985: 78: $1036-9$.

18 Al-Halees ZY, Freeman JB, Burchett H. BrazeauGravelle P. Non-operative management of stomal stenosis after gastroplasty for morbid obesity. Surg Gynuecol Obstet 1986; 162: 349-54.

19 Newham DJ. Harrison RA, Tomkins AM. Clark CG. The strength, contractile properties and radiological density of skeletal muscle before and one year after gastroplasty. Clin Sci 1988; 74: 79-83.

20 Miskowiak J, Honore K, Larsen L. Andersen B. Food intake before and after gastroplasty for morbid obesity. Scand J Gastroenterol 1985; 20: 925-8.

21 Howard AN. The treatment of obesity by starvation and semistarvation. In: Munro JF, ed. The treatment of obesity. Lancaster: MTP Press, 1979: 139-64.

22 Baddeley RM. The surgical management of obesity. In: Taylor S, ed. Recent advances in surgery. Edinburgh: Churchill Livingstone, 1977; 89: 113-32.

23 Joffe SN. Surgical management of obesity. Gut 1981; 22: 242-54. 